\title{
Parameters of Antifiltering Screens, which are around Underground Isolating Structures
}

\author{
Veniamin Khyamyalyainen ${ }^{1, *}$,Eugeny Nurgaliev², and Alexandr Mayorov ${ }^{3}$ \\ ${ }^{1}$ T.F. Gorbachev Kuzbass State Technical University, 650000 Kemerovo, Russia \\ ${ }^{2}$ Scientific research and production Company Ltd "UGM-Service", 650000 Kemerovo, Russia \\ ${ }^{3}$ Federal State Budget Scientific Institution "The Federal Research Center of Coal and Coal \\ Chemistry of Siberian Branch of the Russian Academy of Sciences", 650000, Kemerovo, Russia
}

\begin{abstract}
This article shows results of researches for the definition of rational parameters of technologies for antifiltering screens building around non-hack isolating monolithic bridges with attention to experience of excavations isolation in Kuzbass coal mines. There were evaluated the influence of parameters of antifiltering screen at liquids and gases relocating through rock massif. It has been shown a mathematical model of water filtering and liquid-solid suspensions which are based on cement mixtures through the border rock massif with antifiltering plugging screen.
\end{abstract}

\section{Introduction}

World trends of energy using growth affect at coal industry of country where systematic growth takes place: Kuzbass produced more than 227 million tons of coal in 2016, more than 240 million tons in 2017. Coal mines make new records. In existing geological and mining engineering conditions of underground coal mining (especially in Kuzbass), the most important factor, which reduces tunnelling speed and affects safety, is the necessity of execution of wide complex for seam degassing, mine space ventilation and reducing of methane and oxygen volume in excavated space, implementation of actions for the prevention and fighting with breeding fire. Safety rules describe it. The main technological method of control is the constructing of isolating structures in projected places of mine excavations. The most technologically advanced of these structures are monolithic non-hack bridges. The number of isolating structures is getting bigger every year in Kuzbass and there are more than thousand of them which are exploited.

High-quality isolation providing and localization of excavated space is the most technologically difficult in mine excavations whose fractured border area is too much destroyed. Wherein, considering Kuzbass example, significant quantity of non-hack bridges has been installed and operated without preliminary / following hardening and consolidation of the destroyed border area, which leads to significant relocates of gas through the isolating structures, to the absence of bearing structural bounds and as result bases of industrial safety can be broken.

* Corresponding author: vah@kuzstu.ru 
The necessity of complex rational approach to building and safety maintenance of mines, which is supposed to be constructed with consolidating isolating systems "bridge - plugging screen" which are structurally integrated into the destroyed border space is obvious.

Thus, to improve isolation technologies of mine excavations by non-hack bridges with consolidated border space, the actual point is a foundation of rational parameters of injection cementation and development of the theory of fluid filtering within the boundaries of the plugging screen.

\section{Injection methods of manipulating on the rock massif}

Modern level of development of injection technologies for hardening and compacting of destroyed rock massif has been achieved because of researches of MSU, SBPU, NMRC A.A. Skochinsky, NIIOSP, PA "Specplugginggeology", DonSRCI, MSMU, MakEBI (DonNABA), USMU, KuzSTU, PNRPU, Hydrospecproject, Vedeneev VNIIG, JSC "CSRIB", USRIOMMB, VIOGEM, KuzSRIMinebuilding, IC SB RAS, Scientific research and production Company Ltd "UGM-Service" and other scientific and production companies. Rocks plugging by cement grouts for compacting and water tightness is known in mining [1-14]. Researching process showed that parts of excavations, which have been treated by cement grout for hydroisolation or with fire-prevented and isolating bridges, works much longer than non-treated bordering parts.

During isolation works, preliminary plugging of rock massif takes place before bridges construction, and subsequent lugging takes place after construction of bridges. One of the promising methods is combined method, which based on the technological combination of the bridge body constructing and plugging hardening-compacting screen with changing of physical and mechanical properties of destroyed rocks and with creation of structural bounds with border area of rock. This gives a synergistic effect of increasing of quality and the speed of excavated space isolation. Combined method is exactly the most effective for the construction of consolidated isolating systems "bridge - plugging screen".

The main purpose of injection plugging is hardening of rock for increasing of the stability of mine excavation borders, liquidation of gases and water through an isolating construction.

\section{Plugging screens geometric shape control around bridges}

Figure 1 is given for the analysis of the preliminary and subsequent construction of plugging screen around non-hack bridge, where the conditional longitudinal axial section of mine excavation is shown.

In order to reach a qualitative injection hardening and compacting of destroyed border rock massif, it is necessary to create plugging screen with necessarily conditions of the full filling of fractured volume and penetration of injected plugging grout over the entire area of the rational section $A B C D$. At the same time, it is important to have a mutual dimensional arrangement of injection wells around the bridge, what directly affects size and shape of area of plugging grout diffusion over fractures. The value of the inclination angle of the injection wells toward working face contour, which depends of plugging grout coverage area, injection mode and physical properties of rock massif, is important.

a) Subsequent construction of plugging screen. Point $E$ is an opening of injection well. This point provides technological indention $\Delta \mathrm{H}$ from bridge for swell packer placing in mouth of well, but not crossing line $\mathrm{CD}$. Point $\mathrm{F}$ is a designation of mining face part of injection well 5 , and segment $A B$ is equal to the value $h-$ the depth of destroyed border rock massif around bridge. 


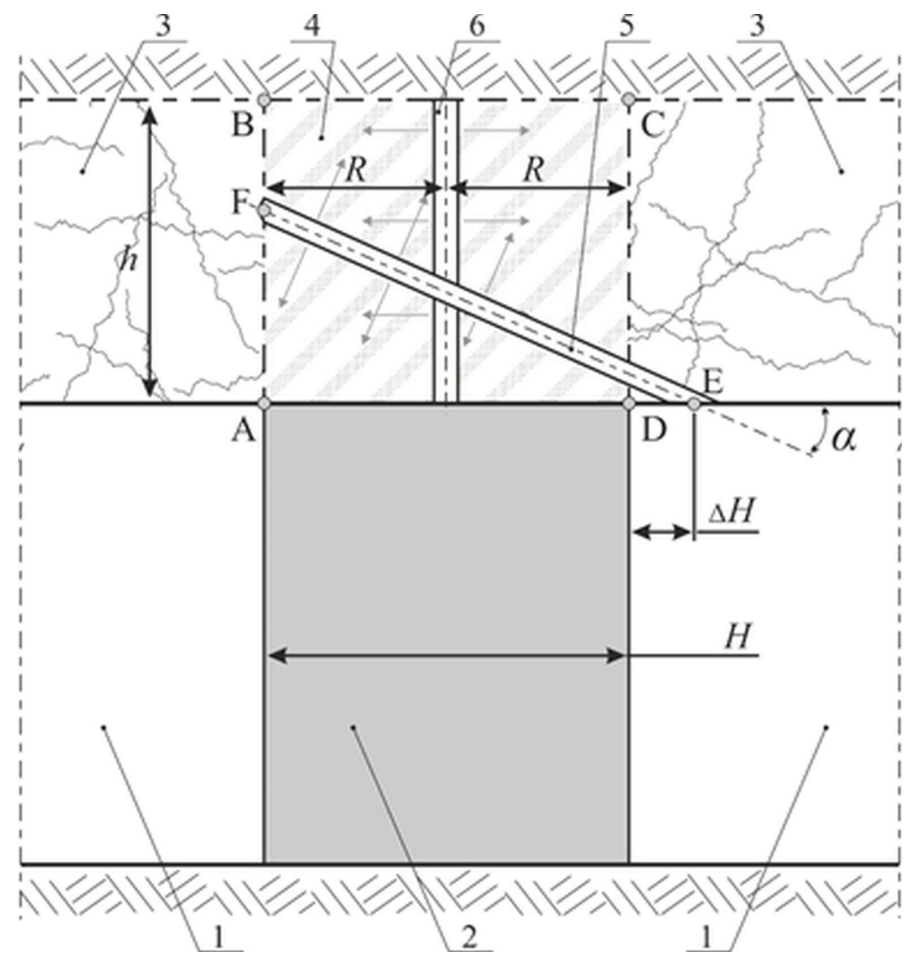

Fig.1. Scheme of pugging screen around non-hack bridge: 1 - mining excavation; 2 - bridge; 3 destroyed border rock massif; 4 - plugging screen; 5 and 6 - injection wells (for preliminary and subsequent plugging resp.).

The engineering method is given to achieve result. This method is based on well-known approach to projecting relatively the angle of inclination of the roofing (Set of Rules 17.13330.2017 "Roofing" Health Rules and Regulations II-26-76). The method allows to calculate the angle of inclination of injection wells relate working face contour (degrees) operating with an correlation of sides of right triangle (with 90 degrees angle) AFE.

b)Preliminary construction of plugging screen. This scheme has more simple implementation if there is free access to bridge installation place. Injection wells 6 are also drilled in harp-form on perimeter, but perpendicular to the contour of excavation. For filling of square of the rational area $\mathrm{ABCD}$ it is necessary to observe the equality of the doubleradius of plugging grout diffusion along rock fractures $2 \mathrm{R}$ bridge thickness.

The distance between injection wells, which are located around as harp-form around bridge, is defined with stipulation of crossing of radii of plugging grout $\mathrm{R}$ diffusion, in accordance with rheological properties and physical parameters of the destroyed border rock massif.

Given schemes minimize the uncontrolled flow of plugging grout to excavation and they increase quality of injection hardening and compacting destroyed border massif around isolating bridges.

\section{Filtering processes simulation}

Further development of perspective technologies for creation of plugging screens, which have been developed by JSC "KuzSRIMinebuilding" and KuzSTU (Kemerovo, Russia), 
allow us to valuate the influence of parameters antifiltration screen on size of water relocating.

A mathematical model of water filtering through rock massif around isolating bridge in conditions of antifiltering screen creation in massif has been developed.

Researching of the process of water filtering through rock massif in the zone of waterproof bridge created a local task with corresponding numbers, paying attention to rational geometric shapes of plugging screen [3]. Water filtering, which is suitable for the linear law of motion and for equation of continuity, was considered. At the same time, the solution is in differential equation for pressure $\mathrm{P}$ allocation at filtration filtering area.

In this case, the permeability coefficient of plugging screen $k_{T}, \mathrm{~m}^{2}$ is a constant. The distribution of the permeability coefficient of an unplugged untouched rock massif $k(r)$, in accordance with the results of well-known mining researches [1-3], is exponential and corresponds to:

$$
k(r)=\frac{k_{O}}{\exp \left[-\frac{R_{B} \ln \left({ }^{k_{O}} / k_{\mathrm{H}}\right)}{R_{\mathrm{H}}-R_{B}} r\right]} \exp \left[-\frac{\ln \left({ }^{k_{o}} / k_{\mathrm{H}}\right)}{R_{\mathrm{H}}-R_{B}} r\right]
$$

$k_{o}$ and $k_{H}$ - permeability coefficients of unplugged massif on contour of excavation and outside from excavation radius influence, corresponding, $\mathrm{m}^{2} ; R_{\mathrm{H}}$ - excavation radius influence (area of changing to massif with low permeability), $m ; R_{B}$ - excavation radius at tunneling, $m$.

Water relocating through the rock massif $\mathrm{Q}$ at the place, where bridge is installed, considered as a total sum of relocates:

at excavation segment with isolating enclosure before bridge

$$
Q_{1}\left(x \in\left[-H-\frac{l_{T}}{2},-\frac{H}{2}\right]\right)
$$

at unplugged excavation segment

$$
Q_{2}\left(x \in\left[-L_{L},-l_{c}-\frac{l_{T}}{2}\right]\right)
$$

at free segment of border massif

$$
Q_{3}\left(x=L_{L}\right)
$$

Where $H$ - the bridge thickness, $m$; $l_{T}$ - the plugging screen thickness, $m$; $l_{c}$ - the thickness of plugged segment of border rock massif before bridge, $m$.

In whole, the analysis of results of numerical calculation allowed us to make following conclusions. Water relocating is mostly under influence of the depth of plugging screen. The influence of the plugins screen depth $h_{T}$ is mostly significant at the range from 0 (excavation border) to $7 \mathrm{~m}$. Plugging screen permeability has less influence than depth. The influence of isolating enclosure before bridge is almost zero. Rock massif plugging should be carried out if the permeability is $k_{o} \geq 0,5 \cdot 10-12, \mathrm{~m}^{2}$. The main water relocating is observed in unplugged segment of excavation.

Plugging screen formation around excavation is defined by the process of grout injection to rock massif. That is why, parameters of injection technology include: grout expenditure in well, injecting pressure, injecting mode, grout concentration, grout diffusion zone, injecting time, wells length. These parameters are interconnected by process of grout filtering in massif and depend of filtering properties of grout. The results of influence evaluation of plugging screen properties on water relocating through massif show that the specificity of technology of injection to massif around bridge is the bigger length of injection wells to 4-6 meters or 
more, and the distribution of permeability coefficient according to the exponential law (3). First of all these noted qualities lead to necessity of valuation of grout discharge to well with attention to permeability diffusion. This question has significant practical meaning, because the solution creates limits for productivity of injection and grout preparation equipment.

The mathematical model of filtering of unstable plugging grouts, which has been developed by JSC "KuzSRIMinebuilding" and KuzSTU, was taken as a basis [1]. Assuming constant values of injection pressure of plugging grout $P_{c \kappa}, P_{a}$, and well radius $R_{c \kappa}, m$, along the length of injection well, an engineering formula has been discovered for definition of a grout expenditure to well with dependence of average plugging radius $R, m$, over the length of well, pressure $P_{c k}$; coefficient of dynamic viscosity of grout $\mu, \mathrm{Pa} \cdot \mathrm{s}$; and filtering properties of plugging massif.

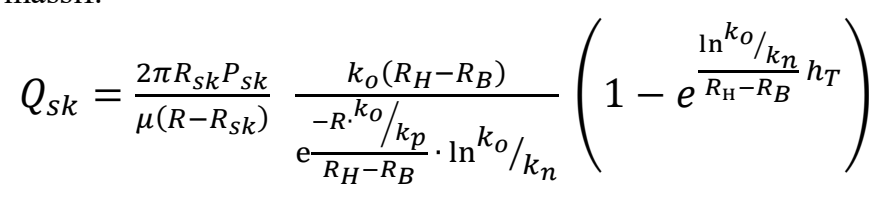

\section{Experience of implementation}

KuzSTU, Institute of coal SB RAS and Scientific research and production Company Ltd "UGM-Service" carried out joint research in area of fluids filtering and area of control of rocks physical and mechanical properties. It allowed to solve the problem of excavations isolation.

Today, research and production Company Ltd "UGM-Service" has been developed new UGM-series compositions, which are based on activated cement and mineral filler, their flow characteristics and physical and mechanical properties have been researched, industrial production (with more than 2 thousands of ton per month volume) is organized. The compositions belong to the lightweight concrete class they have high rates of tough growing, continuance, adhesion.

Wide application of research results on leading coal-mining factories of Kuzbass over previous four years. The brightest detail is the positive result of subsequent construction of plugging screen around bridge No. 7425 . The result was obtained by application of described approaches in conditions of "Raspadskaya-Koksovaya" coal mine. In connection with the fact that sizes of fractures in border massif are different, injection was carried out in two pressure levels: to 0,5 and to $1 \mathrm{MPa}$ for qualitative construction of plugging screen. Each injection step allows to use two stages - the first is carried out with constant expenditure and variable (rising) pressure, the second is carried out with constant pressure and variable (decreasing) expenditure. Filling of fractures groups with different size takes place at each stage. Fractures with size more than $5 \mathrm{~mm}$ were filled at the first stage, at the second stage less than $2 \mathrm{~mm}$. As result, almost all relocates of gas-air mixture through isolating construction were eliminated. Methane volume decrease in front of bridge from $2 \%$ to normal was proven, i.e. more than 4 times; oxygen in used wall space from 19 to $12 \%$, i.e. more than 4 times.

\section{Conclusion}

Rational borders of plugging screen around bridge corresponds to: vertically - bridge thickness, radially - depth of destroyed border zone of rock massif with exponentially reducing permeability coefficient. Minimal value of permeability coefficient on excavation contour is $k_{o}=0,5 \cdot 10^{-12} \mathrm{~m}^{2}$. 
The developed technology of subsequent hardening of destroyed border massif around non-hack bridges includes a set of solutions for creating of radial harp from injection wells, which are inclined above bridge at the angle to contour of seam excavation, which is defined from correlation of bridge thickness, size of destroyed zone and from radius of diffusion of plugging grout.

Parameters of the technology for construction of plugging screen include: grout expenditure to each well, injecting pressure, injecting mode, grout concentration grout diffusion zone, injecting time, wells length. These parameters are interconnected by the process of grout filtering in massif and depend of filtering properties of grout. Observing these conditions and dependences, we can provide efficient hardening and decrease of filtering properties of destroyed rocks in border zone around bridge.

\section{References}

1. V. A. Khyamyalyainen, Y. V. Burkov, P. S. Syrkyn, Cement-grout screen formation around permanent mine excavations (Nedra, Moscow, 1994)

2. V. A. Khyamyalyainen, V. I. Mitrakov, P. S. Syrkyn, Physical and chemical rocks hardening with excavation construction (Nedra, Moscow, 1996)

3. V. A. Khyamyalyainen, G. S. Frankivich, V. A. Zherebtsov, Antifiltering screens creation around water-resistant bridges (KuzSTU, Kemerovo, 2000)

4. A. E. Mayorov, V. A. Khyamyalyainen, Consolidating bracing of mining excavations (RAS-KemSC, Novosibirsk, 2009)

5. A. E. Mayorov, V. A. Khyamyalyainen, Mining Journal, 4, 105-110, (2010)

6. A.E. Mayorov, J. of Mining Sc., 46:2, 82 (2010)

7. E. I. Nurgaliev, A. E. Mayorov, G. N. Rout, Coal journal, 6, 20-23, (2014)

8. Instruction for prevention and firefighting of underground breeding fire on Kuzbass coal mines (FSUC EastSRI, Kemerovo, 2007)

9. E. I. Glauzberg, Theoretical basics of prognosis and prevention of breeding fire (Nedra, Moscow, 1989)

10. V. V. Egoshin, E. V. Kukharenko, I. F. Alexandrovich, Prevention and firefighting of underground breeding fire on Kuzbass coal mines (Kemerovo book publishing, Kemerovo, 1994)

11. Y. Z. Zaslavskiy, B. A. Lopukhin, E. B. Druzhko, Rock massif injection hardening. (Nedra, Moscow, 1984)

12. E. Y. Kipko, Y. A. Polozov, O. Y. Lushnikova, V. A. Lagunov, Complex method of plugging in mine building (Nedra, Moscow, 1984)

13. A. P. Parfenov, Hydroisolating, Mining construction, 7, 24-25 (1989)

14. A. V. Uglyanitsa, V. V. Pershin, Fractured rocks grouting in conditions of preexcavations (KuzSTU, Kemerovo, 1998) 